\title{
ДИАГНОСТИКА ПРЕДИКТОРОВ МЕТАБОЛИЧЕСКОГО СИНДРОМА В ПЕДИАТРИЧЕСКОЙ ПРАКТИКЕ.
}

\author{
Подчиненова Д.В., Самойлова Ю.Г., Олейник О.А.
}

ФГБОУ ВО «Сибирский Государственный Медицинский Университет» Минздрава России, Томск

Цель: установить диагностические параметры висцерального ожирения у детей и подростков по данным биоимпедансметрии.

Материалы и методы: Обследовано 1914 детей и подростков в возрасте от 3 до 18 лет, с различной массой тела. В ходе исследования проводилась оценка антропометрических данных (рост, вес, расчет индекса массы тела (ИМТ)), определение композиционного состава тела с оценкой площади висцерального жира. Для анализа состава тела использовался метод мультичастотной биоимпедансметрии, измерения проводились при помощи аппарата Inbody 770 (Корея).

Далее исследовались уровни инсулина и глюкозы крови натощак. Для расчета инсулинорезистентности (ИР) применяли малую математическую модель гомеостаза глюкозы (Homeostasis Model Assessment - HOMA). Основываясь на полученных данных, с использованием ROC-анализа, были вычислены пороговые значения для показателя площади висцерального жира, ассоциированные с повышенным риском развития ИР у детей и подростков вне зависимости от ИМТ. Результаты: среди всех обследованных (n=1914), 955 человек имели нормальную массу тела (критерий SDS ИМТ <1), а 959 человек (критерий SDS ИМТ $\geq 1$ ) имели избыточную массу или ожирение различной степени. Среди девочек 248 (56,5\%) имели избыточную массу тела, 93 (21,2\%) - ожирение I степени, 60 (13,7\%) - ожирение II степени, 23 (5,2\%) - ожирение III степени, 15 (3,4\%) - ожирение IV степени. У 244 (46,9\%) мальчиков был выявлен избыток массы тела, у 170 (32,7\%) ожирение I степени, у 64 (12,3\%) ожирение II степени, у 31 (6 \%) ожирение III степени, 11 (2,1\%) имели морбидное ожирение. Среди обследованных групп были вычислены пороговые точки в значении площади висцерального жира, которые свидетельствуют о повышении риска развития ИР и соответственно метаболического синдрома (МС) и могут быть использованы в качестве диагностического критерия висцерального ожирения. Возрастная стратификация осуществлялась по классификации ВОЗ (1997 г). Значение площади висцерального жира, ассоциированное с риском развития ИР и висцерального ожирения, согласно результатам ROC-анализа, для девочек в возрасте до 10 лет составило 35,9 $\mathrm{cm}^{2}$ (специфичность - 62\%, чувствительность - 78\%), в группе мальчиков того же возраста пороговая точка была равна $37,3 \mathrm{~cm}^{2}$ (специфичность - 68\%, чувствительность - 76,1\%). Для группы девочекподростков (10 лет и старше) риск развития ИР был повышен при значении площади висцерального

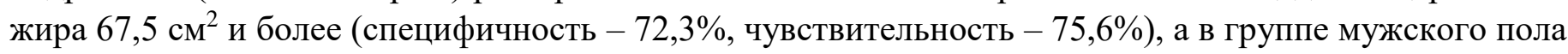
$45,9 \mathrm{~cm}^{2}$ (специфичность - 72,9\%, чувствительность - 93,3\%).

При анализе значений площади висцерального жира, полученных с помощью биоимпедансного анализа, висцеральное ожирение было выявлено среди лиц нормальной массой тела: в $2 \%$ случаев среди девочек младше 10 лет и в 6,7\% для девочек от 10 лет и старше; для мальчиков, до 10 лет процент составил $3,4 \%$, а для подгруппы от 10 лет и более $-8,5 \%$.

Выводы: Таким образом, выявление среди обследованных в декретированные сроки детей и подростков позволит выявить группу риска по развитию ИР и МС, требующую детального наблюдения и проведения лечебно-профилактических мероприятий на ранних сроках развития заболевания. 